\title{
Income drawdown for corporate executives
}

Received (in revised form): 18th March, 2002

\section{Steve Patterson}

has been an IFA for 20 years and has written numerous articles and spoken widely at both regional and national level on retirement planning and pension matters in general. In 1998 he set up Intelligent Pensions Ltd. to provide specialist advice and pension fund management services to higher earners. The company has a team of G60 qualified consultants throughout the UK and has developed sophisticated computer analysis systems for the design and management of private pension funds for individuals. Over 90 per cent of the company's business is obtained by referral from other IFAs as well as solicitors and accountants.

\begin{abstract}
The 1995 Finance Act introduced income drawdown as an alternative to annuities. The freedom to vary pensions in payment to suit changing patterns of expenditure through retirement has proved popular among high earners with money purchase benefits. Hitherto members of defined benefit schemes have not shared in this new freedom as many retirees will be unaware of the opportunities available to them. This paper considers the benefits and pitfalls of restructuring a defined benefit entitlement as retirement approaches.
\end{abstract}

Keywords: taking 'ownership' of pension rights at retirement; investment freedom; income flexibility; capital preservation on death; the benefits and pitfalls

\section{Introduction}

As a method of pension delivery income drawdown has become firmly established as an attractive alternative to annuities for investors in maturing money purchase pension plans. Under a drawdown plan their fund remains invested and the member can withdraw pension income at varying levels to suit their needs. Approximately $\AA^{2 b n}$ per annum or 25 per cent of maturing funds are transferred into drawdown plans instead of annuities. The majority of these are arranged for moderate to high earners - often professional practitioners or business owners. However, opportunities also exist for their counterparts in large corporations whose pension benefits are provided on a salary-related basis provided that they are willing to transfer their benefits before retirement.
The market for income drawdown has been driven by a variety of factors but primarily the unprecedented fall in gilt yields (and hence annuity rates) during the 1990s. In the past some degree of investment risk has been considered a necessary element in the accumulation phase of funding. Under defined benefit schemes this risk has been taken by employers while under money purchase plans the investor takes the risks. Thereafter the need for security in the post-retirement period has been taken for granted. But for money purchase retirees the dramatic reduction in annuity rates has created an environment in which those with substantial funds are now prepared to extend the financial risk into the retirement period. The risks after retirement are more acute for a variety of reasons. 
Retirement is a significant financial watershed for most people since it means the end of their wealth-generating years. Accordingly the opportunity thereafter to compensate for adverse market conditions is often non-existent. But many money purchase benefit holders have some control over their retirement date being professional people or business owners. The financial risk is therefore softened by the ability to continue earning perhaps in a reduced or part time capacity. There is, however, a growing trend for retiring company executives to take up some form of business or consultancy activity rather than give up work altogether.

As legislation stands at present, there is still a requirement to surrender the pension fund and purchase an annuity by age 75 . In its recent consultation document 'Modernising Annuities' the Government made it clear it has no intention of changing the status quo. It is therefore important to bear in mind that in a low inflation era there is the risk that annuity rates may fall even further. Added to this is the opportunity cost of the mortality subsidy inherent in annuities. The investment value of the fund may fail to achieve sufficient growth to compensate for delaying the annuity. This effect is known as 'mortality drag'.

On the face of it income drawdown appears to be a high risk strategy. Nevertheless, the fact that so many wealthy investors are prepared to accept a degree of risk to their pension indicates that there are also strong attractions. This paper considers these and whether they offer benefits for members of occupational defined benefit schemes.

\section{Taking ownership of the pension capital}

As specialists in this field we can, perhaps, claim to have a better understanding of the mentality of drawdown investors than most. While the growth in the market has been driven by the falling annuity rates, the reasons why investors choose income drawdown are much more complex. Two in particular stand out. First, having built up substantial pension funds, most people in this category wish to ensure that they can preserve the capital for their next of kin in the event of premature death. Secondly, there is a great desire to gain or retain control over the retirement fund and the level of pension income that it provides. In both cases the attractions are equally relevant to corporate managers and executives retiring out of defined benefit schemes.

However, in order to appreciate this relevance, it is firstly important to understand and appreciate the capital worth or 'cash equivalent' of the defined benefit pension entitlement. In practice, very few members of such schemes have any real idea of the underlying capital worth of their benefit. It comes as a great surprise for scheme members to find out, for example, that the 'cash equivalent' of a $\mathcal{E} 40,000$ per annum index linked pension for a 60-year-old male will be the best part of $\mathcal{E} 1 \mathrm{~m}$ !

But why should someone with a fixed benefit for life consider giving that up in exchange for a retirement fund which carries no guarantees of income security? As with the majority of higher value money purchase scheme members the attractions are significant provided they are prepared to accept a degree of financial risk. In order to consider the position it is often better to start by taking 'psychological ownership' of the cash equivalent fund and then consider whether the best application of this fund is in the annuity offered by the scheme or the greater freedom and control offered by a pension drawdown plan. The financial and emotional 
considerations are, in fact, precisely the same as for a member of a money purchase plan since these individuals have the same choice of a guaranteed income (through an annuity) or flexibility and control at the risk of lower returns.

Starting from this position it is essential to carry out an assessment in order to measure the relative risk and opportunity cost. This is achieved by carrying out a 'critical yield' analysis. Essentially this is a mathematical calculation of the rate of investment return required under a drawdown plan in order to match the guaranteed income benefit 'given up' as a result of transferring the benefit away from the current scheme.

The critical yield will always be higher than the yields available on long dated gilts for two reasons. The basis for calculating cash equivalent transfer values involves taking account of long term interest rates (gilt yields) and also average life expectancy. The scheme or life office actuary knows that a proportion of members in retirement will die prematurely and this results in a windfall benefit to the scheme which can be used to supplement other members' pensions. This is known as 'mortality subsidy'. Under a drawdown plan there is no mortality subsidy since each drawdown investor's fund passes to the member's own next of kin on death. In order to make up for this the drawdown fund needs to achieve a higher growth rate than the scheme assumes when the transfer value is worked out. This additional growth requirement is known as 'mortality drag'. The second factor is that drawdown plans involve costs and so further investment returns are required to overcome the extra expense.

The 'critical yield' measurement is not exact since it depends upon an assumption about future annuity rates (bearing in mind that under current legislation the drawdown fund will ultimately require to be applied to buy an annuity by age 75 at the latest). Taking account of the significant fall in long-term interest rates and the relatively stable economic conditions that exist at present a fair assumption would be that annuity rates will decline marginally over time due to increasing longevity among the population at large.

Our experience indicates that a typical 'cash equivalent' transfer value close to normal retirement age for a 60-year-old male would require to achieve investment returns of around 1.5 per cent above current gilt yields to overcome the mortality drag. On top of this must be added the expenses of investment management, administration and advice for operating the drawdown arrangement. This will depend on the particular plan adopted but as an indication our own plans involve total annual charges of 1.25 per cent p.a. including the costs of administration, investment management and investment advice. Based on current gilt yields these factors mean that a gross investment return of at least 7.5 per cent p.a. would be required to match the defined pension benefit. This indicates that in order to obtain equivalent value for money at least a moderate degree of investment risk is necessary.

There are, however, certain situations in which achieving equivalent value for money (ie in terms of the retirement income) is not a primary factor. For example, a prospective retiree in poor health with severely reduced life expectancy might consider that preserving the full underlying capital for his spouse or next of kin is significantly more important. Since most defined benefit schemes provide only for a spouses pension of 50 per cent this, in relation to the underlying capital, represents a prospective loss of 50 per 
cent of the cash equivalent on premature death shortly after retiring. In a worst-case scenario where the scheme member is single or the spouse dies first then the capital underlying member's pension is lost altogether.

On the question of investment risk it is important to distinguish between 'absolute' and 'relative' risk. For example, someone with a substantial stock market or property portfolio that meets much of their income requirements is not at significant risk by moving their 'cash equivalent' into a drawdown

arrangement. Furthermore achieving the 'critical yield' on the basis of a 10- or 15-year investment timescale does not necessarily involve significant absolute risk provided a suitably robust investment strategy is in place. The 'relative' risk is therefore dependant on a variety of factors and good advice is essential.

It should also be borne in mind that the 'cash equivalent' transfer value is the actuarial equivalent of the benefits given up. It is therefore by definition actuarially neutral, reflecting the fact that the loss of mortality subsidy is already offset by the better death benefits offered by drawdown. In certain cases, for example, a scheme member who is single, capitalising the pension will create an immediate gain by securing the cash equivalent of the spouse's pension which would otherwise be void.

It is therefore reasonable to assume that someone with a long period of service who is not totally dependent on their pension will be able to take control over their retirement fund without significant risk or loss of value in the process. The transfer itself does not create any immediate material disadvantage provided the scheme offers a fair transfer value. 'Fair' in this context means that the scheme discharges its liability for a guaranteed future income stream at a realistic price that is not detrimental to the remaining members. Nevertheless there can be significant divergence between schemes as even minor differences in actuarial assumptions tend to become magnified in the calculation process. It is therefore necessary to consider each case on its merits and this is done by carrying out a proper analysis of the transfer value offered which is an essential element of the advice process.

\section{Flexible income to suit changing needs}

The second attraction of taking control of the retirement fund is that it enables members to enjoy the significant freedom of deciding how much income they wish to obtain at each stage of retirement. Although drawdown arrangements are subject to certain overall limits (see Table 1) generally speaking the specific objectives of most individuals can be achieved. This might, for example, be to provide higher income in the earlier years of retirement and less in later life. This reflects the general pattern of expenditure under which most people wish to take advantage of their greater energy and better health to enjoy a more active retirement in the early years while anticipating a more passive and sedate lifestyle later on.

In addition to preserving capital in the event of premature death and matching the pension income to lifestyle objectives, pension drawdown also offers significant tax planning opportunities. It is not uncommon, particularly among senior executives, to take up consultancy posts or non-executive directorships following full-time employment. The opportunity to draw only sufficient pension as is needed to supplement other income enables less tax to be paid than would be the case if the whole pension were in payment. Furthermore, the 
Table 1: Minimum and maximum withdrawals as a percentage of the drawdown fund at different ages (as at October 2001)

\begin{tabular}{lcl}
\hline Age & Maximum & Minimum \\
\hline 60 & $8 \%$ & $2.8 \%$ \\
65 & $9.1 \%$ & $3.2 \%$ \\
70 & $10.6 \%$ & $3.7 \%$ \\
\hline
\end{tabular}

excess remains in the fund growing tax-free until it is required, rather than being accumulated outside the pension fund where further tax on interest or gains may otherwise arise.

Furthermore, a significant proportion of this 'income' in the early years can be made up of instalments of tax-free cash based on the tax-free lump sum entitlement transferred from the occupational scheme. This arrangement is known as 'phased drawdown'. The degree of 'phasing' can be precisely controlled on a year-to-year basis to suit the investor's specific needs. Between the right to raise or lower the level of withdrawals each year within the permitted limits and the option to activate the fund on a phased basis the additional flexibility is very significant indeed.

\section{Other tax planning opportunities}

A further potential tax benefit is in the area of estate planning. Any lump-sum death benefits under a drawdown plan can usually be paid to nominated beneficiaries bypassing the investor's estate for inheritance tax purposes. Furthermore, by controlling the income flow to meet the investor's expenditure needs, the residual pension fund capital can be accumulated with a view to securing a lifetime income for later years sufficient to match the long term needs of the investor and his or her spouse. This enables the investor to take advantage of the positive benefits of mortality subsidy in later life and, more particularly, provides the opportunity for lifetime gifting of other assets which otherwise might be relied upon to sustain a secure income in later years.

Ultimately, the objective should be to provide only sufficient index-linked income to meet the investor's expenditure requirements and no more. This involves a degree of analysis that 'targets' the longer-term requirements and thereby defines the parameters within which IHT planning opportunities can be based. Good advice will always leave a margin for error and any significant capital gifting will often be best delayed until the risk of a shortfall in the pension is minimal.

Additional estate planning arrangements can also be used to make best possible use of the death benefits under drawdown plans. Considerable care and attention is necessary but options such as spousal bypass trusts are not uncommon. When implemented effectively, such an arrangement will avoid the capital forming part of the surviving spouse's own estate while providing the facility to provide a regular income. In some arrangements this 'income' is actually provided in the form of a series of loans repayable on death, thereby reducing the spouse's estate even further. The ultimate beneficiaries will typically be the children or grandchildren, but great care should be taken over the structure and wording of the trust otherwise there can be unforeseen and expensive consequences.

\section{Planning for retirement freedom}

The most flexible form of income drawdown plan is a special type of Personal Pension Plan set up under trust and providing access to a broad range of investment media. Expert advice is essential since only the specialists in this 
field are able to design suitable investment strategies. This means they also undertake regular monitoring until all the benefits are finally secured under annuities. It will rarely be appropriate to keep the whole fund in drawdown right through to age 75 . A safe solution will involve managing the investment risk, including identifying suitable opportunities to make partial annuity purchases when market conditions are favourable.

In some cases, a special actuarial test is required before benefits can be transferred. This applies to all scheme members over 45 who are deemed by the Inland Revenue to be 'high earners' ie have earned more than the 'earnings cap' in any of the previous six years and also to controlling directors. The reason for the test is to avoid excessive transfers taking place, but failure is only likely where a member's benefits are already close to the maximum Inland Revenue limits. In practice this is a 'pass or fail' test. Most high earners in defined benefit schemes should pass the test, but those who do not will not be permitted to transfer to a Personal Pension Plan. They will have the option to use a less flexible form of arrangement know as a 'buyout drawdown plan' but since this continues to be constrained to occupational pension limits and offers little advantage in relation to death benefits, it is rarely used.

Although members of 'defined benefit' schemes will generally have a statutory entitlement to transfer the 'cash equivalent' of their pension to another arrangement such as a drawdown plan this right lapses one year before normal retirement age. Within this period (or after normal retirement age) members are unable to demand the transfer of their benefits but on early retirement this should not present a problem. For those not taking early retirement the planning should therefore take place at least one year before retirement and, in those circumstances where income drawdown is likely to be appropriate, members should give formal notification to the trustees of their wish to transfer benefits. While trustees are not under any obligation to meet this requirement, the notice period will mean that they should be in a position to make an appropriate allowance within the investment of the fund. This should restrict any justification by the trustees for declining the transfer request.

\section{Pensions from previous employments}

Quite apart from those scheme members who remain with their employer until retirement, there are a significant number of individuals who have 'paid up' pension entitlements having already left service with their previous employer. The question as to whether or not these individuals should transfer to an arrangement that offers income drawdown depends on a similar range of factors.

An essential difference is that the revaluation rate of the paid-up pension entitlement must also be taken into account. Theoretically, at least, deferred members should also be able to obtain better value for money provided they are prepared to accept at least a degree of financial risk. This, again, depends upon the trustees offering fair value for value for money on a transfer. As with the retirement position the scheme is able to discharge its liability for a future pension benefit and should do so at a reasonable price. Nevertheless, some schemes offer better transfer values than others and in all cases proper independent analysis is essential. For those where the transfer value is reasonable the opportunity to enhance the benefits can be significant, 
in addition to the potential merits available through income drawdown as described above.

\section{Conclusion}

It will be evident from this brief summary that all corporate executives should be considering the option of transferring their pension entitlement to a drawdown plan at or before retirement.
Those with significant 'paid up' pensions from previous employments should also consider the benefits of taking control of the cash equivalent fund. The opportunity to gain further growth on their benefits, enjoy more control over income and preserve the capital for their families on death will be extremely attractive. Nevertheless drawdown is not suitable for everyone and does involve risks. 